\title{
Kinetic Features of Reactive Diffusion between Sn-5Au Alloy and Ni at Solid-State Temperatures
}

\author{
Yu-ichi Yato*1 and Masanori Kajihara*2 \\ Department of Materials Science and Engineering, Tokyo Institute of Technology, Yokohama 226-8502, Japan
}

\begin{abstract}
In order to examine microstructure evolution at the interconnection between the $\mathrm{Sn}$-base solder and $\mathrm{Au} / \mathrm{Ni} / \mathrm{Cu}$ multilayer conductor alloys during energization heating, the kinetics of the reactive diffusion between a binary $\mathrm{Sn}-5 \mathrm{at} \%$ Au alloy and pure Ni was experimentally observed at solid-state temperatures. Sandwich $(\mathrm{Sn}-\mathrm{Au}) / \mathrm{Ni} /(\mathrm{Sn}-\mathrm{Au})$ diffusion couples were prepared by a diffusion bonding technique, and then isothermally annealed at temperatures of $T=433,453$ and $473 \mathrm{~K}$ for various periods up to $1057 \mathrm{~h}$. During annealing, $\mathrm{AuNiSn}_{8}$ and $\mathrm{Ni}_{3} \mathrm{Sn}_{4}$ compound layers are formed along the $(\mathrm{Sn}-\mathrm{Au}) / \mathrm{Ni}$ interface in the diffusion couple. The total thickness of the compound layers is expressed as a power function of the annealing time. The exponent of the power function is close to 0.5 at $T=453-473 \mathrm{~K}$, and equal to 0.7 at $T=433 \mathrm{~K}$. Therefore, volume diffusion is the rate-controlling process for the growth of the compound layers at $T=453-473 \mathrm{~K}$, but interface reaction contributes to the rate-controlling process at $T=433 \mathrm{~K}$. The growth of the compound layers occurs slower for the reactive diffusion between the $\mathrm{Sn}-5 \mathrm{Au}$ alloy and Ni than for that between $\mathrm{Sn}$ and $\mathrm{Au}$, but faster for that between the $\mathrm{Sn}-5 \mathrm{Au}$ alloy and Ni than for that between $\mathrm{Sn}$ and Ni. [doi: $10.2320 /$ matertrans.47.2277]
\end{abstract}

(Received April 10, 2006; Accepted July 4, 2006; Published September 15, 2006)

Keywords: diffusion bonding, reactive diffusion, intermetallic compounds, bulk diffusion, solder, conductor

\section{Introduction}

Owing to high electrical conductivity, $\mathrm{Cu}$-base alloys are widely used as conductor materials in electronic industry. When the Cu-base conductor alloy is interconnected with a Sn-base solder alloy, $\mathrm{Cu}-\mathrm{Sn}$ compounds are formed at the interconnection during soldering and then grow during heating under energization conditions. ${ }^{1-9)}$ Since the $\mathrm{Cu}-\mathrm{Sn}$ compounds are brittle and possess high electrical resistivities, the growth of the compounds deteriorates the electrical and mechanical properties of the interconnection. The $\mathrm{Cu}$ base alloy is usually plated with a Ni layer in order to inhibit the formation of the $\mathrm{Cu}-\mathrm{Sn}$ compounds, and the Ni layer is plated with a $\mathrm{Au}$ layer for improvement of the corrosion resistance. If the $\mathrm{Au}$ layer of the $\mathrm{Au} / \mathrm{Ni} / \mathrm{Cu}$ multilayer conductor alloy is very thin, however, the $\mathrm{Au}$ layer completely dissolves into the molten solder during soldering. ${ }^{10-15)}$ As a consequence, the reactive diffusion between the Ni layer and the molten solder occurs immediately after the complete dissolution of the Au layer, and then a binary $\mathrm{Ni}-\mathrm{Sn}$ compound is formed at the interface. Such a compound will grow under the energization heating conditions and may also deteriorate the electrical and mechanical properties at the interconnection.

Chen and Chen ${ }^{16)}$ experimentally observed the reactive diffusion in the binary $\mathrm{Sn} / \mathrm{Ni}$ system. In their experiment, sandwich $\mathrm{Sn} / \mathrm{Ni} / \mathrm{Sn}$ diffusion couples were prepared by a soldering technique and then annealed at temperatures between $T=433$ and $473 \mathrm{~K}$. Their observation indicates that a layer of $\mathrm{Ni}_{3} \mathrm{Sn}_{4}$ is produced along the $\mathrm{Sn} / \mathrm{Ni}$ interface in the diffusion couple during soldering and grows during annealing. The thickness of the $\mathrm{Ni}_{3} \mathrm{Sn}_{4}$ layer is nearly proportional to the square root of the annealing time. Such a relationship is called the parabolic relationship. The parabolic relationship implies that the growth of the $\mathrm{Ni}_{3} \mathrm{Sn}_{4}$ layer

\footnotetext{
${ }^{* 1}$ Graduate Student, Tokyo Institute of Technology

${ }^{* 2}$ Corresponding author, E-mail: kajihara@materia.titech.ac.jp
}

is controlled by volume diffusion. However, in the soldering technique, the $\mathrm{Ni}_{3} \mathrm{Sn}_{4}$ layer with a certain thickness is formed during soldering before annealing. Therefore, it is not so easy to distinguish the growth rate during annealing from the formation rate during soldering. Consequently, the soldering technique is not appropriate to observe the growth behavior of the $\mathrm{Ni}_{3} \mathrm{Sn}_{4}$ layer during annealing at solid-state temperatures.

The reactive diffusion in various binary and ternary systems was experimentally observed at solid-state temperatures using sandwich diffusion couples prepared by a diffusion bonding technique in previous studies. ${ }^{17-30)}$ As to the binary $\mathrm{Sn} / \mathrm{Ni}$ system, ${ }^{17)} \mathrm{Sn} / \mathrm{Ni} / \mathrm{Sn}$ diffusion couples were isothermally annealed at $T=433,453$ and $473 \mathrm{~K}$ for various periods. Along the $\mathrm{Sn} / \mathrm{Ni}$ interface in the diffusion couple, $\mathrm{Ni}_{3} \mathrm{Sn}_{4}$ is produced as a layer at $T=453$ and $473 \mathrm{~K}$ but as fine particles at $T=433 \mathrm{~K}$. On the other hand, $\mathrm{AuSn}_{4}, \mathrm{AuSn}_{2}$ and AuSn layers are formed in $\mathrm{Sn} / \mathrm{Au} / \mathrm{Sn}$ diffusion couples at $T=393-473 \mathrm{~K},{ }^{18-20)}$ and $\mathrm{Cu}_{6} \mathrm{Sn}_{5}$ and $\mathrm{Cu}_{3} \mathrm{Sn}$ layers are produced in $\mathrm{Sn} / \mathrm{Cu} / \mathrm{Sn}$ diffusion couples at $T=433-$ $473 \mathrm{~K}^{21)}$ In the binary $\mathrm{Sn} / \mathrm{Au}, \mathrm{Sn} / \mathrm{Cu}$ and $\mathrm{Sn} / \mathrm{Ni}$ systems, the total thickness of the compound layers is described as a power function of the annealing time. The exponent of the power function is mostly smaller than 0.5 at the experimental annealing temperatures. This indicates that grain boundary diffusion contributes to the rate-controlling process for the growth of the compound layers and grain growth takes place at certain rates in the compound layers. At each annealing temperature and time, the total thickness is about one order of magnitude smaller for the $\mathrm{Cu}-\mathrm{Sn}$ compound layers than for the $\mathrm{Au}-\mathrm{Sn}$ compound layers, but the thickness of the $\mathrm{Ni}_{3} \mathrm{Sn}_{4}$ layer is less than half of the total thickness of the $\mathrm{Cu}-\mathrm{Sn}$ compound layers. As a result, the Ni layer acts as an effective inhibitor against the reactive diffusion between the $\mathrm{Au} / \mathrm{Ni} /$ $\mathrm{Cu}$ multilayer conductor and Sn-base solder alloys during energization heating after the complete dissolution of the $\mathrm{Au}$ layer into the molten solder.

When the Au layer of the $\mathrm{Au} / \mathrm{Ni} / \mathrm{Cu}$ multilayer conductor 
alloy is sufficiently thick, however, the Au-Sn compounds are formed during soldering and then grow during energization heating. ${ }^{10-15)}$ If the Au layer is uniformly depleted during growth of the $\mathrm{Au}-\mathrm{Sn}$ compounds, the Ni layer will be reacted with the $\mathrm{Au}-\mathrm{Sn}$ compounds after complete depletion of the $\mathrm{Au}$ layer. In order to examine characteristic features of such a reaction, the reactive diffusion in the ternary $(\mathrm{Sn}-\mathrm{Ni}) / \mathrm{Au}$ system was experimentally observed at solid-state temperatures using $(\mathrm{Sn}-\mathrm{Ni}) / \mathrm{Au} /(\mathrm{Sn}-\mathrm{Ni})$ diffusion couples in a previous study. ${ }^{22)}$ Here, the notation $(\mathrm{A}-\mathrm{B}) / \mathrm{C}$ indicates that reactive diffusion takes place between a binary A-B alloy and a pure $\mathrm{C}$ metal at appropriate annealing temperatures. In that experiment, binary $\mathrm{Sn}-\mathrm{Ni}$ alloys with concentrations of 1,3 and 5 mass $\% \mathrm{Ni}$ were used to prepare the diffusion couples by the diffusion bonding technique. The diffusion couples were isothermally annealed at $T=433-473 \mathrm{~K}$. Due to annealing, $\mathrm{AuNiSn} \mathrm{A}_{8}, \mathrm{AuSn}_{4}, \mathrm{AuSn}_{2}$ and AuSn layers are produced along the $(\mathrm{Sn}-\mathrm{Ni}) / \mathrm{Au}$ interface in the diffusion couple. Also in this case, the total thickness of the compound layers is expressed as a power function of the annealing time, and the exponent of the power function takes values between 0.3 and 0.4. This deduces that the same rate-controlling process as the binary $\mathrm{Sn} / \mathrm{Au}, \mathrm{Sn} / \mathrm{Cu}$ and $\mathrm{Sn} / \mathrm{Ni}$ systems works for the ternary $(\mathrm{Sn}-\mathrm{Ni}) / \mathrm{Au}$ system. However, the overall growth rate of the compound layers is greater in the ternary $(\mathrm{Sn}-\mathrm{Ni}) / \mathrm{Au}$ system than in the binary $\mathrm{Sn} / \mathrm{Au}$ system. This means that the reactive diffusion in the binary $\mathrm{Sn} / \mathrm{Au}$ system is accelerated by the formation of $\mathrm{AuNiSn}_{8}$ due to the reaction of Ni with $\mathrm{AuSn}_{4}$ at $T=433-473 \mathrm{~K}^{22}$ )

If the $\mathrm{Au}$ layer of the $\mathrm{Au} / \mathrm{Ni} / \mathrm{Cu}$ multilayer conductor alloy is completely depleted during soldering and the $\mathrm{Au}-\mathrm{Sn}$ compounds are non-uniformly produced in the molten solder, the $\mathrm{Au}-\mathrm{Sn}$ compounds and the Sn-base solder will be simultaneously reacted with the Ni layer during energization heating. In order to examine kinetic features of such a complex reaction, the reactive diffusion in the ternary ( $\mathrm{Sn}-$ $\mathrm{Au} / \mathrm{Ni}$ system was experimentally observed at solid-state temperatures in the present study. Sandwich $(\mathrm{Sn}-\mathrm{Au}) / \mathrm{Ni} /$ ( $\mathrm{Sn}-\mathrm{Au}$ ) diffusion couples were prepared from pure $\mathrm{Ni}$ and a binary $\mathrm{Sn}-5$ at\% Au alloy by the diffusion bonding technique and then isothermally annealed at $T=433-473 \mathrm{~K}$ for various periods. The growth behavior of compound layers was observed in a metallographical manner. On the basis of the observation, the rate-controlling process was discussed for the growth of compound layers.

\section{Experimental}

A polycrystalline binary $\mathrm{Sn}-\mathrm{Au}$ alloy containing 5 at $\%$ of Au was prepared as a $30 \mathrm{~g}$ button ingot by argon arc melting from pure $\mathrm{Sn}$ and $\mathrm{Au}$ with purity of $99.99 \%$. The ingot was homogenized in an evacuated silica capsule at a temperature of $T=473 \mathrm{~K}$ for $284 \mathrm{~h}$, followed by water quenching without breaking the capsule. Plate specimens with a dimension of $12 \mathrm{~mm} \times 5 \mathrm{~mm} \times 1 \mathrm{~mm}$ were cut from the ingot, and then the two surfaces with an area of $12 \mathrm{~mm} \times 5 \mathrm{~mm}$ of each plate specimen were mechanically polished on 1000 emery paper. One of the two polished surfaces was again mechanically polished on 1500-4000 emery papers until a depth of $100 \mu \mathrm{m}$ and then finished using diamond with a diameter of $1 \mu \mathrm{m}$. The mechanically polished plate specimen was chemically polished in an etchant consisting of $13 \mathrm{vol} \%$ of nitric acid, $37 \mathrm{vol} \%$ of hydrochloric acid and $50 \mathrm{vol} \%$ of ethanol.

A polycrystalline pure $\mathrm{Ni}$ specimen was prepared as a $25 \mathrm{~g}$ button ingot by argon arc melting from pure Ni with purity of $99.97 \%$. Plate specimens with a size of $10 \mathrm{~mm} \times 4 \mathrm{~mm} \times$ $2 \mathrm{~mm}$ were cut from the button ingot and then cold rolled to a thickness of $0.1 \mathrm{~mm}$. Sheet specimens with a dimension of $20 \mathrm{~mm} \times 7 \mathrm{~mm} \times 0.1 \mathrm{~mm}$ were cut from the cold rolled specimens and then separately annealed in evacuated silica capsules at $1223 \mathrm{~K}$ for $2 \mathrm{~h}$, followed by air cooling without breaking the capsules. The annealed sheet specimens were chemically polished in an etchant composed of $9 \mathrm{vol} \%$ of nitric acid, $18 \mathrm{vol} \%$ of hydrochloric acid and $73 \mathrm{vol} \%$ of ethanol.

After chemical polishing, a $\mathrm{Ni}$ sheet specimen was immediately sandwiched between the finished surfaces of two freshly prepared $\mathrm{Sn}-\mathrm{Au}$ plate specimens in ethanol by a technique used in previous studies. ${ }^{17-23)}$ The $(\mathrm{Sn}-\mathrm{Au}) / \mathrm{Ni} /$ $(\mathrm{Sn}-\mathrm{Au})$ couples were completely dried and then heat treated for diffusion bonding in an oil bath with silicone oil at $T=433,453$ and $473 \mathrm{~K}$ for 192,72 and $24 \mathrm{~h}$, respectively. After the heat treatment, the diffusion couples were isothermally annealed at $T=433,453$ and $473 \mathrm{~K}$ for various times up to $985 \mathrm{~h}$. The summation of the heat-treating and annealing times is hereafter merely denominated the annealing time $t$. Cross-sections of the annealed diffusion couples were mechanically polished using diamond with diameters of 15,3 and $1 \mu \mathrm{m}$ and then finished with an OP-S liquid by Struers Ltd. The microstructure of the cross-section was observed with a back-scattered electron image (BEI) by scanning electron microscopy (SEM) and with an optical microscope $(\mathrm{OM})$. The composition of each phase was measured on the cross-section by electron probe microanalysis (EPMA).

\section{Results and Discussion}

\subsection{Microstructure}

Typical micrographs of OM for the cross-sections of the annealed diffusion couples are shown in Fig. 1. The ( $\mathrm{Sn}-$ $5 \mathrm{Au}) / \mathrm{Ni} /(\mathrm{Sn}-5 \mathrm{Au})$ diffusion couple is hereafter merely called the $\mathrm{Sn}-5 \mathrm{Au}$ diffusion couple. Figure 1(a) indicates the micrograph for the $\mathrm{Sn}-5 \mathrm{Au}$ diffusion couple with $T=$ $433 \mathrm{~K}$ and $t=12 \mathrm{~h}\left(4.32 \times 10^{5} \mathrm{~s}\right)$. In this figure, the regions on the upper and lower sides are the Sn-5Au alloy, and the horizontal band with a thickness of about $100 \mu \mathrm{m}$ is the $\mathrm{Ni}$ specimen. As can be seen, sound interconnection is realized at the interface between the $\mathrm{Sn}-5 \mathrm{Au}$ alloy and the $\mathrm{Ni}$ specimen. However, no compound layer is clearly observed at the interface. As a result, annealing was carried out for much longer periods at $T=433 \mathrm{~K}$. On the other hand, Fig. 1(b) shows the micrograph for the $\mathrm{Sn}-5 \mathrm{Au}$ diffusion couple with $T=473 \mathrm{~K}$ and $t=48 \mathrm{~h}\left(1.73 \times 10^{5} \mathrm{~s}\right)$. In this case, a layer composed of various compounds with different contrasts is formed along each interface. Such a layer grows mainly towards the $\mathrm{Sn}-5 \mathrm{Au}$ alloy but slightly towards the $\mathrm{Ni}$ specimen. The microstructure in Fig. 1(b) is magnified in Fig. 2(a). This figure indicates a micrograph of BEI. In Fig. 2(a), the regions on the upper and lower sides are the Sn- 

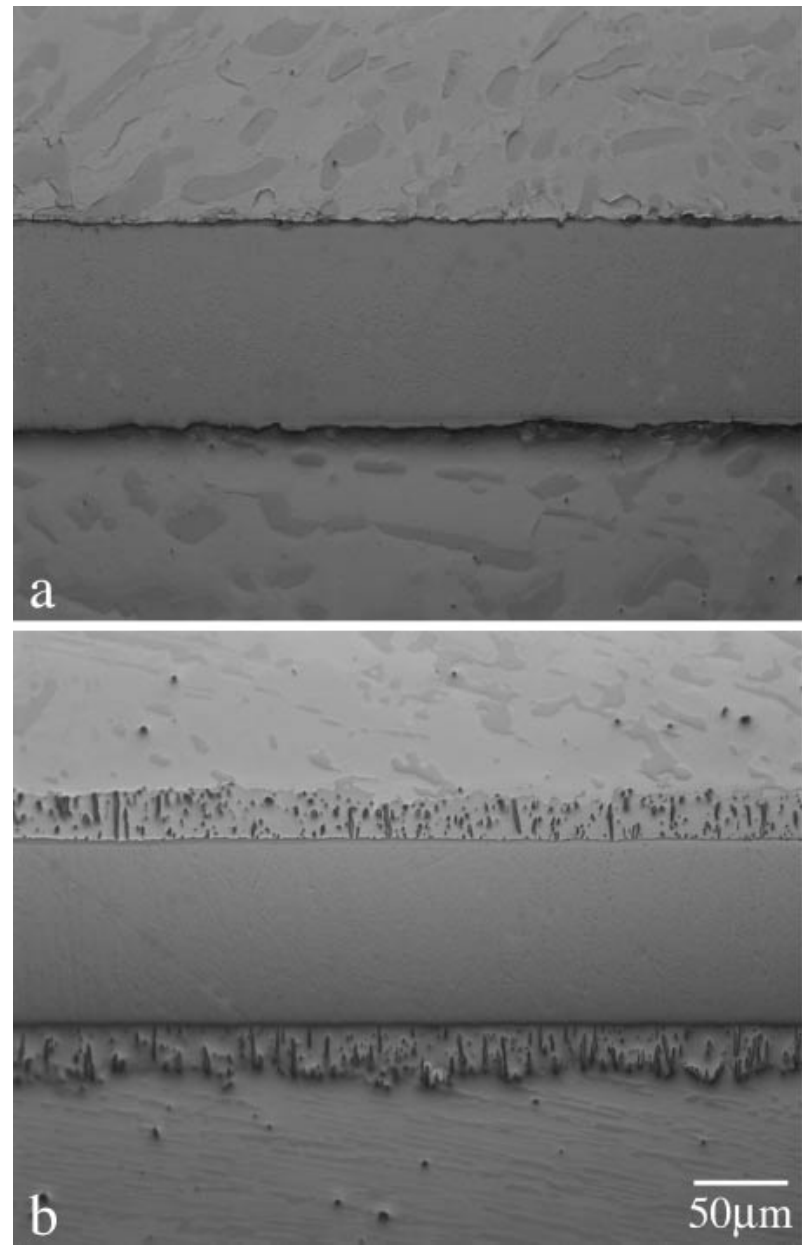

Fig. 1 Optical micrographs of cross-sections for the $\mathrm{Sn}-5 \mathrm{Au}$ diffusion couples annealed (a) at $T=433 \mathrm{~K}$ for $t=12 \mathrm{~h}\left(4.32 \times 10^{4} \mathrm{~s}\right)$ and (b) at $T=473 \mathrm{~K}$ for $t=48 \mathrm{~h}\left(1.73 \times 10^{5} \mathrm{~s}\right)$

5Au alloy and the Ni specimen, respectively. As to the $\mathrm{Sn}-$ $5 \mathrm{Au}$ alloy, coarse bright grains are distributed in a dark matrix. The chemical composition of each phase was measured by EPMA. According to the EPMA measurement, the bright grain and the dark matrix are $\mathrm{AuSn}_{4}$ and the primary solid-solution phase of $\mathrm{Sn}$, respectively. A phase diagram in the binary $\mathrm{Au}-\mathrm{Sn}$ system $^{31)}$ indicates that the $\mathrm{Sn}$ phase is in equilibrium with $\mathrm{AuSn}_{4}$ at $T<490 \mathrm{~K}$. Furthermore, the solubility of $\mathrm{Au}$ in the $\mathrm{Sn}$ phase is less than 0.2 at\%. ${ }^{31)}$ Thus, the $\mathrm{Sn}+\mathrm{AuSn}_{4}$ two-phase microstructure is stable for the $\mathrm{Sn}-5 \mathrm{Au}$ alloy at $T=433-473 \mathrm{~K}$. In contrast, a layer consisting of bright and dark compounds is produced along the $(\mathrm{Sn}-\mathrm{Au}) / \mathrm{Ni}$ interface as mentioned earlier. The EPMA measurement shows that the bright and dark compounds are $\mathrm{AuNiSn}_{8}$ and $\mathrm{Ni}_{3} \mathrm{Sn}_{4}$, respectively. As can be seen in Fig. 2(a), $\mathrm{Ni}_{3} \mathrm{Sn}_{4}$ is formed as a slightly wavy thin layer along the interface between the $\mathrm{AuNiSn}_{8}$ layer and the $\mathrm{Ni}$ specimen, and dispersed as fine particles in the $\mathrm{AuNiSn}_{8}$ layer. The thickness is much smaller for the $\mathrm{Ni}_{3} \mathrm{Sn}_{4}$ layer than for the $\mathrm{AuNiSn}_{8}$ layer. This means that interdiffusion takes place much faster across the $\mathrm{AuNiSn}_{8}$ layer than across the $\mathrm{Ni}_{3} \mathrm{Sn}_{4}$ layer. ${ }^{32)}$ The same type of microstructure as Fig. 2(a) was observed for most of the annealed diffusion couples. On the other hand, Fig. 2(b) indicates the BEI micrograph for the $\mathrm{Sn}-5 \mathrm{Au}$ diffusion couple with $T=473 \mathrm{~K}$ and $t=722 \mathrm{~h}$
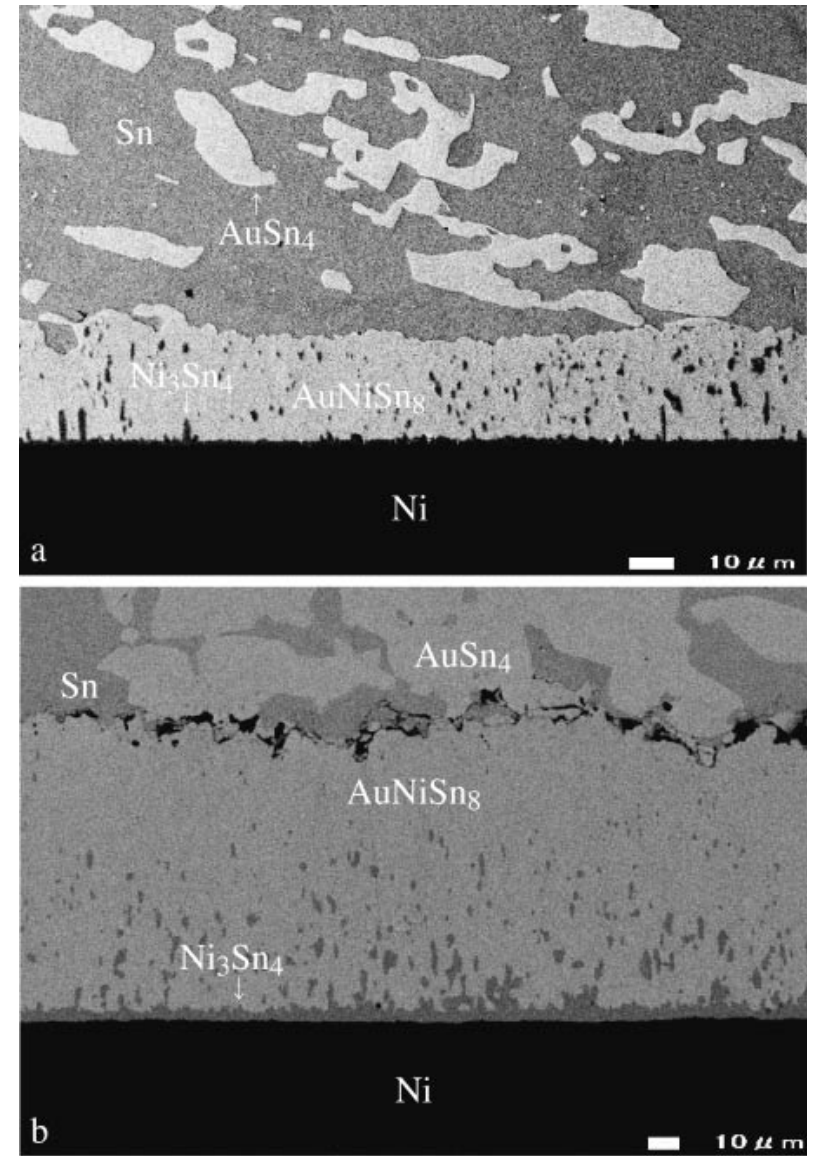

Fig. 2 Back-scattered electron images of cross-sections for the $\mathrm{Sn}-5 \mathrm{Au}$ diffusion couples annealed at $T=473 \mathrm{~K}$ for (a) $t=48 \mathrm{~h}\left(1.73 \times 10^{5} \mathrm{~s}\right)$ and (b) $t=722 \mathrm{~h}\left(2.60 \times 10^{6} \mathrm{~s}\right)$.

$\left(2.60 \times 10^{6} \mathrm{~s}\right)$. As can be seen, the $\mathrm{AuNiSn}_{8}$ and $\mathrm{Ni}_{3} \mathrm{Sn}_{4}$ layers are produced also in this diffusion couple. In Fig. 2(b), however, voids with a dark contrast are recognized along the interface between the $\mathrm{AuNiSn}_{8}$ layer and the $\mathrm{Sn}-5 \mathrm{Au}$ alloy. Such voids are considered to form due to the Kirkendall effect. The occurrence of the Kirkendall effect indicates that the interdiffusion occurs according to a vacancy mechanism. The formation of voids was clearly observed only for the diffusion couples with $T=473 \mathrm{~K}$ and $t=722$ and $840 \mathrm{~h}$ $\left(2.60 \times 10^{6}\right.$ and $\left.3.02 \times 10^{6} \mathrm{~s}\right)$.

Recently, a phase diagram in the ternary $\mathrm{Au}-\mathrm{Ni}-\mathrm{Sn}$ system was experimentally determined by Liu et al. ${ }^{33)}$ According to their result, a three-phase equilibrium of $\mathrm{Sn}+\mathrm{AuSn}_{4}+$ $\mathrm{Ni}_{3} \mathrm{Sn}_{4}$ as well as two-phase equilibria of $\mathrm{Sn}+\mathrm{AuSn}_{4}, \mathrm{Sn}+$ $\mathrm{Ni}_{3} \mathrm{Sn}_{4}$ and $\mathrm{AuSn}_{4}+\mathrm{Ni}_{3} \mathrm{Sn}_{4}$ appears at the $\mathrm{Sn}$-rich corner of the isothermal section with $T=473 \mathrm{~K}$. The solubility of $\mathrm{Ni}$ in $\mathrm{AuSn}_{4}$ is 11.5 at $\%$ at $T=473 \mathrm{~K}^{33)}$ This yields the composition $\mathrm{Au}_{0.85} \mathrm{Ni}_{1.15} \mathrm{Sn}_{8}$. The composition $\mathrm{AuNiSn}_{8}$ is close to $\mathrm{Au}_{0.85} \mathrm{Ni}_{1.15} \mathrm{Sn}_{8}$. Consequently, the microstructure for the compound layers in the $\mathrm{Sn}-5 \mathrm{Au}$ diffusion couple is well explained by the phase equilibria in the ternary $\mathrm{Au}-\mathrm{Ni}-$ Sn system.

\subsection{Growth behavior of intermetallic layer}

From the cross-sectional BEI micrographs like Fig. 2, the total thickness $l$ of the compound layers was evaluated by the equation 


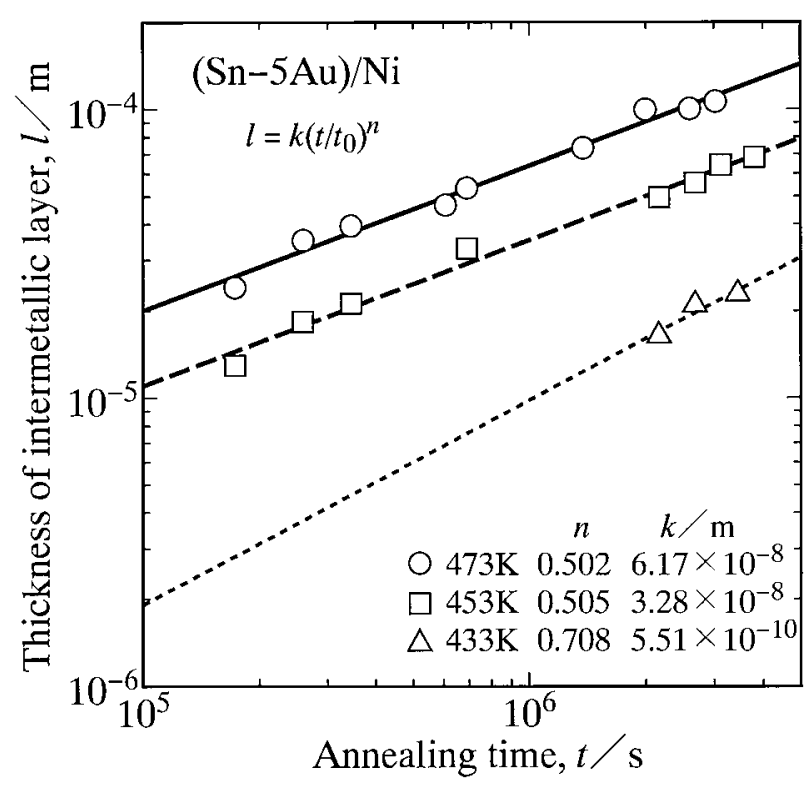

Fig. 3 The total thickness $l$ of the intermetallic layer versus the annealing time $t$ for the $\mathrm{Sn}-5 \mathrm{Au}$ diffusion couple at $T=433,453$ and $473 \mathrm{~K}$ shown as open triangles, squares and circles, respectively. Straight lines indicate the calculations from eq. (2).

$$
l=A / w
$$

where $A$ and $w$ are the total area and the total length of the compound layers, respectively, on the cross-section. Hereafter, the layer composed of various compounds is called the intermetallic layer. At each annealing time, $l$ was calculated from eq. (1) using the total values of $A$ and $w$ for various cross-sections. The results of $T=433,453$ and $473 \mathrm{~K}$ are shown as open triangles, squares and circles, respectively, in Fig. 3. In this figure, the ordinate indicates the logarithm of the thickness $l$, and the abscissa shows the logarithm of the annealing time $t$. As can be seen, the thickness $l$ monotonically increases with increasing annealing time $t$. The plotted points at each annealing temperature lie well on a straight line. This deduces that $l$ is expressed as a power function of $t$ by the following equation:

$$
l=k\left(t / t_{0}\right)^{n} \text {. }
$$

Here, $t_{0}$ is unit time, $1 \mathrm{~s}$. It is adopted to make the argument $t / t_{0}$ of the power function dimensionless. The proportionality coefficient $k$ has the same dimension as the thickness $l$, but the exponent $n$ is dimensionless. From the plotted points in Fig. 3, the values of $k$ and $n$ were evaluated by the leastsquares method. The evaluated values are indicated in Fig. 3. Using these values of $k$ and $n$, the thickness $l$ was calculated as a function of the annealing time $t$ from eq. (2). The results of $T=433,453$ and $473 \mathrm{~K}$ are shown as dotted, dashed and solid lines, respectively, in Fig. 3. At each annealing time, the thickness $l$ increases with increasing annealing temperature $T$. Thus, the higher the annealing temperature is, the larger the overall growth rate of the intermetallic layer becomes. As mentioned in Section 3.1, the Kirkendall voids are formed along the interface between the $\mathrm{AuNiSn}_{8}$ layer and the Sn-5Au alloy at $T=473 \mathrm{~K}$ for $t=722$ and $840 \mathrm{~h}$ $\left(2.60 \times 10^{6}\right.$ and $\left.3.02 \times 10^{6} \mathrm{~s}\right)$. However, the two open circles for these annealing times are located well on the solid line of
$T=473 \mathrm{~K}$ in Fig. 3. Thus, it is concluded that formation of the Kirkendall voids hardly affects the growth rate of the intermetallic layer.

The results of $T=453$ and $473 \mathrm{~K}$ in Fig. 3 are plotted again as open circles with solid lines in Figs. 4(a) and (b), respectively. As mentioned in Section 1, the reactive diffusion was experimentally observed at solid-state temperatures for the binary $\mathrm{Sn} / \mathrm{Ni}^{17)}$ and $\mathrm{Sn} / \mathrm{Au}^{18-20)}$ systems using the $\mathrm{Sn} / \mathrm{Ni} / \mathrm{Sn}$ and $\mathrm{Sn} / \mathrm{Au} / \mathrm{Sn}$ diffusion couples, respectively, in previous studies. The $\mathrm{Sn} / \mathrm{Au} / \mathrm{Sn}$ and $\mathrm{Sn} / \mathrm{Ni} / \mathrm{Sn}$ diffusion couples are denoted by the $\mathrm{Au}$ and $\mathrm{Ni}$ diffusion couples, respectively. The intermetallic layer consisting of $\mathrm{AuSn}_{4}$, $\mathrm{AuSn}_{2}$ and AuSn is formed at $T=393-473 \mathrm{~K}$ in the $\mathrm{Au}$ diffusion couple, but that composed of only $\mathrm{Ni}_{3} \mathrm{Sn}_{4}$ is produced at $T=453-473 \mathrm{~K}$ in the Ni diffusion couple. The experimental values of $l$ for the $\mathrm{Au}$ and $\mathrm{Ni}$ diffusion couples are represented as open squares and triangles, respectively, in Fig. 4. From these open symbols, $k$ and $n$ in eq. (2) were evaluated by the least-squares method. The evaluated values are shown in Fig. 4. Using these values of $k$ and $n, l$ was calculated as a function of $t$ from eq. (2). The results for the $\mathrm{Au}$ and $\mathrm{Ni}$ diffusion couples are indicated as dashed and dotted lines, respectively, in Fig. 4. At each annealing temperature and time, the thickness $l$ is about one order of magnitude greater for the $\mathrm{Sn}-5 \mathrm{Au}$ diffusion couple than for the Ni diffusion couple, but smaller for the $\mathrm{Sn}-5 \mathrm{Au}$ diffusion couple than for the $\mathrm{Au}$ diffusion couple. In the $\mathrm{Sn}-5 \mathrm{Au}$ diffusion couple, the intermetallic layer consisting of AuNiSn 8 and $\mathrm{Ni}_{3} \mathrm{Sn}_{4}$ is produced by the reactive diffusion between $\mathrm{Ni}$ and $\mathrm{Sn}+\mathrm{AuSn}_{4}$. The overall growth rate of the intermetallic layer is greater for the reactive diffusion between $\mathrm{Ni}$ and $\mathrm{Sn}+\mathrm{AuSn}_{4}$ than for that between $\mathrm{Ni}$ and $\mathrm{Sn}$ but smaller for that between $\mathrm{Ni}$ and $\mathrm{Sn}+\mathrm{AuSn}_{4}$ than for that between $\mathrm{Au}$ and $\mathrm{Sn}$. Thus, the Ni layer still works as an inhibitor against the reactive diffusion between the $\mathrm{Au} / \mathrm{Ni} /$ $\mathrm{Cu}$ multilayer conductor and Sn-base solder alloys during energization heating, even if $\mathrm{AuSn}_{4}$ is non-uniformly formed in the molten solder and the $\mathrm{Au}$ layer of the $\mathrm{Au} / \mathrm{Ni} / \mathrm{Cu}$ multilayer conductor alloy is completely depleted during soldering.

\subsection{Rate-controlling process}

The values of the exponent $n$ for the $\mathrm{Sn}-5 \mathrm{Au}, \mathrm{Au}$ and $\mathrm{Ni}$ diffusion couples are plotted against the annealing temperature $T$ as open circles, squares and triangles, respectively, in Fig. 5. Here, the ordinate and the abscissa indicate $n$ and $T$, respectively. The reactive diffusion in the ternary $\mathrm{Sn} /(\mathrm{Au}-$ $\mathrm{Ni}$ ) system was experimentally observed using $\mathrm{Sn} /(\mathrm{Au}-$ $27 \mathrm{Ni}) / \mathrm{Sn}$ and $\mathrm{Sn} /(\mathrm{Au}-46 \mathrm{Ni}) / \mathrm{Sn}$ diffusion couples in a previous study. ${ }^{29)}$ The $\mathrm{Sn} /(\mathrm{Au}-27 \mathrm{Ni}) / \mathrm{Sn}$ and $\mathrm{Sn} /(\mathrm{Au}-$ $46 \mathrm{Ni}$ )/Sn diffusion couples are merely called the $\mathrm{Au}-27 \mathrm{Ni}$ and $\mathrm{Au}-46 \mathrm{Ni}$ diffusion couples, respectively. During isothermal annealing at $T=433-473 \mathrm{~K}$, the intermetallic layer composed of $\mathrm{Au}_{1.5} \mathrm{Ni}_{0.5} \mathrm{Sn}_{8}$ and $\mathrm{AuNi}_{2} \mathrm{Sn}_{4}$ is formed along the $\mathrm{Sn} /(\mathrm{Au}-\mathrm{Ni})$ interface in the $\mathrm{Au}-46 \mathrm{Ni}$ diffusion couple, but that consisting of $\mathrm{Au}_{1.7} \mathrm{Ni}_{0.3} \mathrm{Sn}_{8}, \mathrm{AuSn}_{2}$ and $\mathrm{Au}_{6} \mathrm{Ni}_{4} \mathrm{Sn}_{15}$ dispersed with fine particles of $\mathrm{AuNi}_{2} \mathrm{Sn}_{4}$ is produced along the interface in the $\mathrm{Au}-27 \mathrm{Ni}$ diffusion couple. Also for these diffusion couples, the total thickness $l$ of the intermetallic layer is expressed as a power function of the annealing time $t$ 


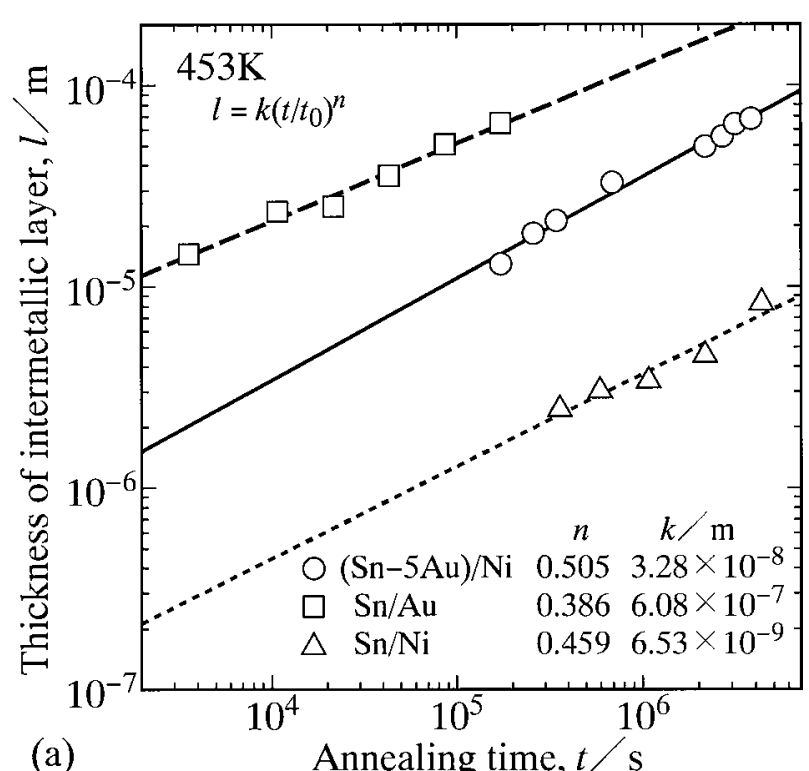

(a)

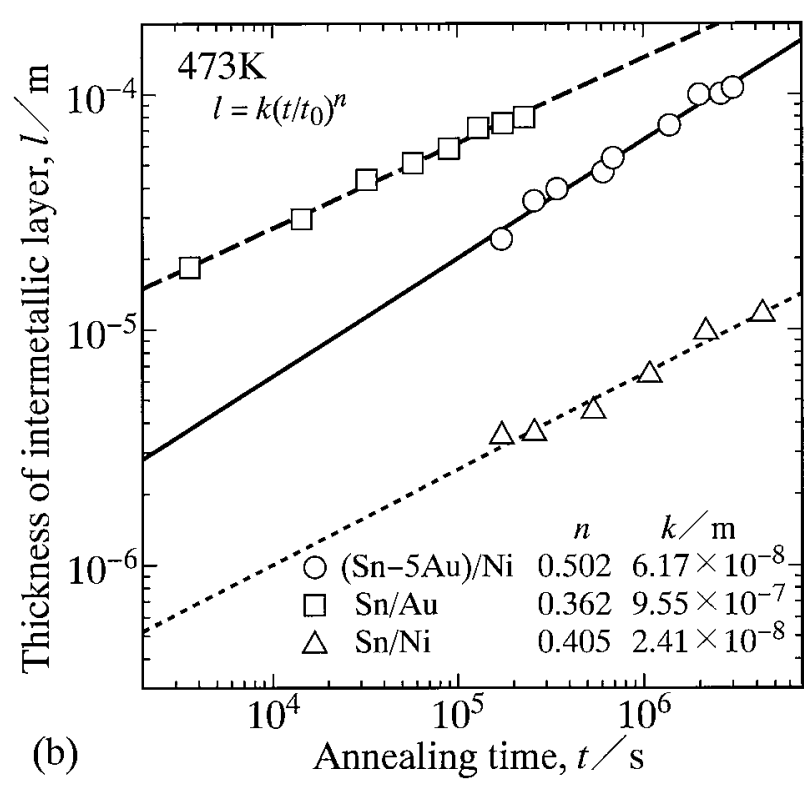

Fig. 4 The results of $T=453$ and $473 \mathrm{~K}$ in Fig. 3 are represented as open circles with solid lines in (a) and (b), respectively. The results for the $\mathrm{Ni}^{17}$ and $\mathrm{Au}^{19,20)}$ diffusion couples are also shown as open triangles and squares, respectively.

by eq. (2). The values of the exponent $n$ for the $\mathrm{Au}-27 \mathrm{Ni}$ and $\mathrm{Au}-46 \mathrm{Ni}$ diffusion couples ${ }^{29)}$ are represented as open rhombuses and inverse-triangles, respectively, in Fig. 5.

As to the $\mathrm{Au}$ diffusion couple, $n$ is equal to 0.36 at $T=473 \mathrm{~K}$, and monotonically increases with decreasing annealing temperature. ${ }^{18-20)}$ At $T=393 \mathrm{~K}, n$ is close to 0.5 . When the volume diffusion of the constituent elements in each phase is the rate-controlling process for the growth of the intermetallic layer, $n$ is equal to 0.5 . On the other hand, the growth will be governed by the grain boundary diffusion along grain boundaries with a finite thickness in the intermetallic layer at low annealing temperatures where the volume diffusion is practically frozen out. If grain growth takes place in the intermetallic layer, the volume fraction of the grain boundaries monotonically decreases with increasing annealing time. Such decrease in the volume fraction

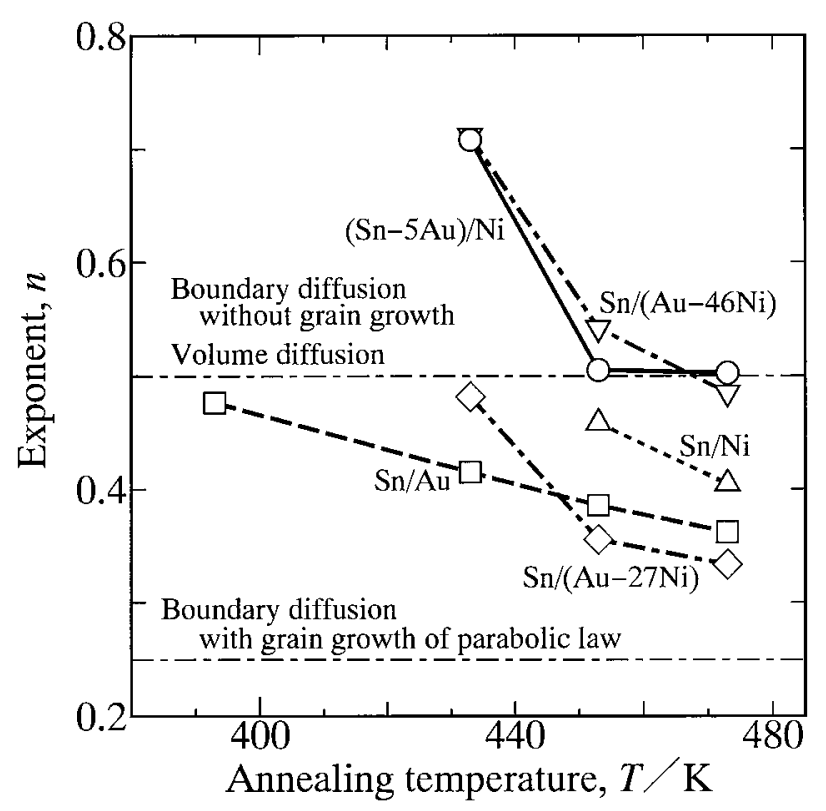

Fig. 5 The exponent $n$ versus the annealing temperature $T$ for the $\mathrm{Sn}-5 \mathrm{Au}$ diffusion couple shown as open circles. The results for the $\mathrm{Ni},{ }^{17)} \mathrm{Au},{ }^{19,20}$ ) $\mathrm{Au}-27 \mathrm{Ni}$ and $\mathrm{Au}-46 \mathrm{Ni}^{29)}$ diffusion couples are also indicated as open triangles, squares, rhombuses and inverse-triangles, respectively.

results in the decrement of the effective cross-section, and decelerates the grain boundary diffusion. Thus, $n$ becomes smaller than 0.5 . When the grain size is proportional to the square root of the annealing time, $n$ is equal to $0.25 .^{34)}$ If the grain growth occurs very sluggishly, the volume fraction of the grain boundaries remains almost constant during annealing. In such a case, the effective cross-section for the grain boundary diffusion hardly varies, and hence $n$ is almost equal to 0.5 . From the temperature dependence of $n$ for the $\mathrm{Au}$ diffusion couple in Fig. 5, it is concluded that the grain boundary diffusion as well as the volume diffusion contributes to the rate-controlling process and the grain growth takes place at certain rates at higher annealing temperatures. ${ }^{19,20)}$ As the annealing temperature decreases, the contribution of the grain boundary diffusion becomes remarkable, but the grain growth slows down. Similar temperature dependence of the rate-controlling process was recognized also for the $\mathrm{Ni}^{17}$ ) and $\mathrm{Au}-27 \mathrm{Ni}^{29)}$ diffusion couples.

On the other hand, for the $\mathrm{Sn}-5 \mathrm{Au}$ diffusion couple, $n$ is close to 0.5 at $T=453-473 \mathrm{~K}$, but equal to 0.7 at $T=433 \mathrm{~K}$. Like the $\mathrm{Au}, \mathrm{Ni}$ and $\mathrm{Au}-27 \mathrm{Ni}$ diffusion couples, the grain growth in the intermetallic layer may occur at certain rates also for the $\mathrm{Sn}-5 \mathrm{Au}$ diffusion couple. Nevertheless, $n$ is close to 0.5 at $T=453-473 \mathrm{~K}$ for the $\mathrm{Sn}-5 \mathrm{Au}$ diffusion couple. This means that the volume diffusion is the rate-controlling process. ${ }^{25)}$ At $T=433 \mathrm{~K}$, however, $n$ is equal to 0.7 for the $\mathrm{Sn}-5 \mathrm{Au}$ diffusion couple. Thus, interface reaction contributes to the rate-controlling process. ${ }^{27,30)}$ According to the $\mathrm{OM}$ micrographs in Fig. 1, the intermetallic layer grows mainly towards the $\mathrm{Sn}-\mathrm{Au}$ alloy but slightly towards the $\mathrm{Ni}$ specimen. Furthermore, the most predominant compound determining the overall growth rate of the intermetallic layer is $\mathrm{AuNiSn}_{8}$. Therefore, the growth rate of the intermetallic layer is dominantly determined by the migration rate of the $\mathrm{AuNiSn}_{8} /(\mathrm{Sn}-\mathrm{Au})$ interface. As a consequence, for the $\mathrm{Sn}-$ 
5Au diffusion couple, the interface reaction at the migrating $\mathrm{AuNiSn}_{8} /(\mathrm{Sn}-\mathrm{Au})$ interface becomes the bottleneck for the growth of the intermetallic layer at $T=433 \mathrm{~K}$. The same temperature dependence of the rate-controlling process as the $\mathrm{Sn}-5 \mathrm{Au}$ diffusion couple was observed for the $\mathrm{Au}-46 \mathrm{Ni}$ diffusion couple. ${ }^{29)}$

This type of rate-controlling process was experimentally examined for the reactive diffusion in the ternary $(\mathrm{Cu}-\mathrm{Sn}) /$ $\mathrm{Nb}$ system in a previous study. ${ }^{27)}$ In that experiment, $(\mathrm{Cu}-$ $\mathrm{Sn}) / \mathrm{Nb} /(\mathrm{Cu}-\mathrm{Sn})$ diffusion couples with a concentration of 8.3 at\% Sn were isothermally annealed at temperatures of $T=923-1053 \mathrm{~K}$. During annealing, a layer of $\mathrm{Nb}_{3} \mathrm{Sn}$ is formed along the $(\mathrm{Cu}-\mathrm{Sn}) / \mathrm{Nb}$ interface in the diffusion couple, and the thickness $l$ of the $\mathrm{Nb}_{3} \mathrm{Sn}$ layer increases in proportion to a power function of the annealing time $t$. Thus, the growth of the $\mathrm{Nb}_{3} \mathrm{Sn}$ layer is also described by eq. (2). Since the $\mathrm{Nb}_{3} \mathrm{Sn}$ layer grows mainly towards the $\mathrm{Nb}$ specimen, the migration of the $\mathrm{Nb}_{3} \mathrm{Sn} / \mathrm{Nb}$ interface principally governs the growth of the $\mathrm{Nb}_{3} \mathrm{Sn}$ layer. The exponent $n$ in eq. (2) is nearly equal to unity at $T=923-973 \mathrm{~K}$ and monotonically decreases from 1 to 0.8 with increasing annealing temperature from $T=973 \mathrm{~K}$ to $T=1053 \mathrm{~K}$. This indicates that the interface reaction at the $\mathrm{Nb}_{3} \mathrm{Sn} / \mathrm{Nb}$ interface is the rate-controlling process for the growth of the $\mathrm{Nb}_{3} \mathrm{Sn}$ layer at $T=923-973 \mathrm{~K}$ and the volume diffusion across the $\mathrm{Nb}_{3} \mathrm{Sn}$ layer contributes to the rate-controlling process at $T=973-1053 \mathrm{~K}$. In the temperature range of $T=923-973 \mathrm{~K}$, the temperature dependence of the proportionality coefficient $k$ in eq. (2) was expressed as

$$
k=k_{0} \exp \left(-Q_{k} / R T\right),
$$

and then the activation enthalpy $Q_{k}$ was evaluated to be $150 \mathrm{~kJ} / \mathrm{mol}^{27)}$ Here, $k_{0}$ and $R$ are the pre-exponential factor and the gas constant, respectively. The value $Q_{k}=150$ $\mathrm{kJ} / \mathrm{mol}$ represents the activation enthalpy of the interface reaction at the $\mathrm{Nb}_{3} \mathrm{Sn} / \mathrm{Nb}$ interface. On the other hand, the corresponding value of $Q_{k}$ for the rate-controlling process of the volume diffusion was estimated as $100 \mathrm{~kJ} / \mathrm{mol}^{27)}$ The smaller the value of $Q_{k}$ is, the less sensitive the temperature dependence of $k$ becomes. As the annealing temperature increases, the rate of the interface reaction increases more remarkably than that of the volume diffusion. Therefore, the interface reaction is no longer the bottleneck for the migration of the $\mathrm{Nb}_{3} \mathrm{Sn} / \mathrm{Nb}$ interface at higher annealing temperatures. This is the reason why the interface reaction is the rate-controlling process at $T=923-973 \mathrm{~K}$ but the volume diffusion contributes to the rate-controlling process at $T=973-1053 \mathrm{~K}$. Such an explanation may be possible also for the temperature dependence of the rate-controlling process for the $\mathrm{Sn}-5 \mathrm{Au}$ and $\mathrm{Au}-46 \mathrm{Ni}$ diffusion couples. Unfortunately, however, the value of $Q_{k}$ is not known for the interface reaction in these diffusion couples. Consequently, the explanation is not available for the $\mathrm{Sn}-5 \mathrm{Au}$ and $\mathrm{Au}-46 \mathrm{Ni}$ diffusion couples, though the activation enthalpy of the volume diffusion has been estimated below.

When the reactive diffusion is controlled by the volume diffusion, the growth of the intermetallic layer is expressed by the following equation: ${ }^{32)}$

$$
l^{2}=K t .
$$

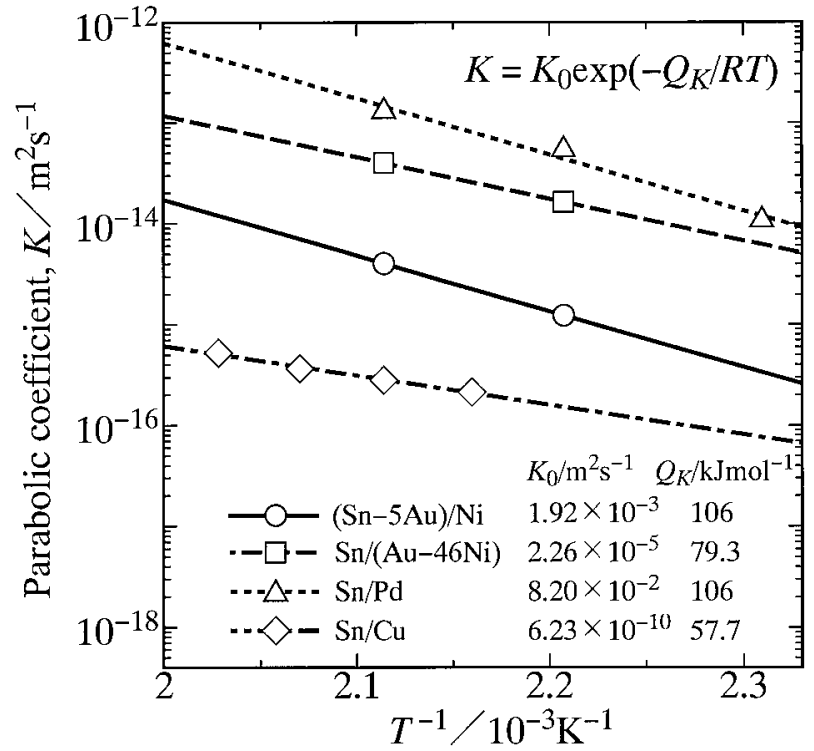

Fig. 6 The parabolic coefficient $K$ versus the reciprocal of the annealing temperature $T$ for the $\mathrm{Sn}-5 \mathrm{Au}$ diffusion couple shown as open circles. The results for the $\mathrm{Pd},{ }^{25)} \mathrm{Cu}^{39)}$ and $\mathrm{Au}-46 \mathrm{Ni}^{29)}$ diffusion couples are also indicated as open triangles, rhombuses and squares, respectively. Straight lines show the calculations from eq. (5).

Equation (4) is a formula of the parabolic relationship, where $K$ is the parabolic coefficient with a dimension of $\mathrm{m}^{2} / \mathrm{s}$. As mentioned above, the volume diffusion is the rate-controlling process for the $\mathrm{Sn}-5 \mathrm{Au}$ diffusion couple at $T=453-473 \mathrm{~K}$. Thus, the values of $K$ at $T=453$ and $473 \mathrm{~K}$ for the $\mathrm{Sn}-5 \mathrm{Au}$ diffusion couple were evaluated from eq. (4) using the open squares and circles, respectively, in Fig. 3 by the leastsquares method. The evaluation gives $K=1.23 \times 10^{-14}$ and $4.03 \times 10^{-14} \mathrm{~m}^{2} / \mathrm{s}$ at $T=453$ and $473 \mathrm{~K}$, respectively. These values are plotted against the annealing temperature $T$ as open circles in Fig. 6. In this figure, the ordinate shows the logarithm of $K$, and the abscissa indicates the reciprocal of $T$. The temperature dependence of $K$ is described by the following equation with certain accuracy: ${ }^{35-38)}$

$$
K=K_{0} \exp \left(-Q_{K} / R T\right) .
$$

Here, $K_{0}$ and $Q_{K}$ are the pre-exponential factor and the activation enthalpy, respectively. Interconnecting the two open circles with a solid line in Fig. 6, we obtain $K_{0}=$ $1.92 \times 10^{-3} \mathrm{~m}^{2} / \mathrm{s}$ and $Q_{K}=106 \mathrm{~kJ} / \mathrm{mol}$ for the $\mathrm{Sn}-5 \mathrm{Au}$ diffusion couple. As mentioned earlier, the growth of the intermetallic layer is controlled by the volume diffusion also for the Au-46Ni diffusion couple at $T=453-473 \mathrm{~K}$. The values of $K$ for the $\mathrm{Au}-46 \mathrm{Ni}$ diffusion couple ${ }^{29)}$ are represented as open squares in Fig. 6. Interconnection of the two open squares with a dashed line yields $K_{0}=2.26 \times$ $10^{-5} \mathrm{~m}^{2} / \mathrm{s}$ and $Q_{K}=79.3 \mathrm{~kJ} / \mathrm{mol} .^{29)}$

The reactive diffusion in the binary $\mathrm{Sn} / \mathrm{Pd}$ system was experimentally observed at $T=433-473 \mathrm{~K}$ using $\mathrm{Sn} / \mathrm{Pd} / \mathrm{Sn}$ diffusion couples in a previous study. ${ }^{25)}$ The $\mathrm{Sn} / \mathrm{Pd} / \mathrm{Sn}$ diffusion couple is denominated the Pd diffusion couple. For the Pd diffusion couple, the intermetallic layer is composed of $\mathrm{PdSn}_{4}, \mathrm{PdSn}_{3}$ and $\mathrm{PdSn}_{2}$ at $T=433 \mathrm{~K}$ but only $\mathrm{PdSn}_{4}$ and $\mathrm{PdSn}_{3}$ at $T=453$ and $473 \mathrm{~K}$. Although the grain growth surely occurs in the intermetallic layer, the thickness $l$ is 
almost proportional to the square root of the annealing time $t$ at $T=433-473 \mathrm{~K}^{25}{ }^{25}$ This guarantees that the growth of the intermetallic layer is governed by the volume diffusion. The values of $K$ for the Pd diffusion couple are represented as open triangles in Fig. 6. From the open triangles, $K_{0}=$ $8.20 \times 10^{-2} \mathrm{~m}^{2} / \mathrm{s}$ and $Q_{K}=106 \mathrm{~kJ} / \mathrm{mol}$ are obtained by the least-squares method. In contrast, Onishi and Fujibuchi experimentally observed the reactive diffusion in the binary $\mathrm{Sn} / \mathrm{Cu}$ system at $T=463-493 \mathrm{~K}$ using $\mathrm{Sn} / \mathrm{Cu}$ diffusion couples. ${ }^{39)}$ The $\mathrm{Sn} / \mathrm{Cu}$ diffusion couple is denoted by the $\mathrm{Cu}$ diffusion couple. The values of $K$ for the $\mathrm{Cu}$ diffusion couple are also represented as open rhombuses in Fig. 6. For the open rhombuses, $K_{0}=6.23 \times 10^{-10} \mathrm{~m}^{2} / \mathrm{s}$ and $Q_{K}=57.7$ $\mathrm{kJ} / \mathrm{mol}$ were reported by Onishi and Fujibuchi. ${ }^{39)}$ Using these values of $K_{0}$ and $Q_{K}, K$ was calculated as a function of $T$ from eq. (5). The results for the $\mathrm{Pd}$ and $\mathrm{Cu}$ diffusion couples are indicated as dotted and dashed-and-dotted lines, respectively, in Fig. 6. As can be seen, $K$ is smaller for the $\mathrm{Sn}-5 \mathrm{Au}$ diffusion couple than for the $\mathrm{Au}-46 \mathrm{Ni}$ and $\mathrm{Pd}$ diffusion couples, but greater for the $\mathrm{Sn}-5 \mathrm{Au}$ diffusion couple than for the $\mathrm{Cu}$ diffusion couple. The overall growth rate of the intermetallic layer is close to each other for the $\mathrm{Pd}$ and $\mathrm{Au}$ diffusion couples. ${ }^{19,20,25)}$ Thus, the reactive diffusion between $\mathrm{Ni}$ and $\mathrm{Sn}+\mathrm{AuSn}_{4}$ occurs more slowly than that between $\mathrm{Au}$ and $\mathrm{Sn}$ but more rapidly than that between $\mathrm{Cu}$ and $\mathrm{Sn}$. Consequently, Ni layer still acts as an inhibitor against the reactive diffusion between the $\mathrm{Au} / \mathrm{Ni} / \mathrm{Cu}$ multilayer conductor and Sn-base solder alloys during energization heating, even if $\mathrm{AuSn}_{4}$ is formed in the molten solder and the Au layer is completely depleted during soldering. However, the kinetics of this reactive diffusion is faster than that of the reactive diffusion between the $\mathrm{Cu}$-base conductor and $\mathrm{Sn}$ base solder alloys. The value $Q_{K}=106 \mathrm{~kJ} / \mathrm{mol}$ for the $\mathrm{Sn}-$ $5 \mathrm{Au}$ and $\mathrm{Pd}$ diffusion couples is rather close to that $Q_{K}=$ $79.3 \mathrm{~kJ} / \mathrm{mol}$ for the $\mathrm{Au}-46 \mathrm{Ni}$ diffusion couple, but greater than that $Q_{K}=57.7 \mathrm{~kJ} / \mathrm{mol}$ for the $\mathrm{Cu}$ diffusion couple. When the intermetallic layer consists of compound layers with parallel interfaces and temperature dependencies of interdiffusion coefficients in relevant phases are known for reactive diffusion in a binary system, $Q_{K}$ is quantitatively related with the activation enthalpies $Q$ of the interdiffusion coefficients in an analytical manner. ${ }^{35-37)}$ Even in such a case, however, complex information of $Q$ for the relevant phases is included in $Q_{K}$. Hence, it may not be valid to discuss the ratecontrolling process of the reactive diffusion only from the value of $Q_{K}$.

\section{Conclusions}

The reactive diffusion in the ternary $(\mathrm{Sn}-\mathrm{Au}) / \mathrm{Ni}$ system was experimentally observed at solid-state temperatures using the sandwich $(\mathrm{Sn}-5 \mathrm{Au}) / \mathrm{Ni} /(\mathrm{Sn}-5 \mathrm{Au})$ diffusion couple prepared by the diffusion bonding technique. The diffusion couple was isothermally annealed in the temperature range between $T=433$ and $473 \mathrm{~K}$ for various times up to $1057 \mathrm{~h}$ in the oil bath with silicone oil. In this temperature range, the coarse grains of $\mathrm{AuSn}_{4}$ are distributed in the primary solidsolution phase of $\mathrm{Sn}$ for the binary $\mathrm{Sn}-5 \mathrm{Au}$ alloy. During annealing, the $\mathrm{AuNiSn}_{8}$ and $\mathrm{Ni}_{3} \mathrm{Sn}_{4}$ layers are formed along the $(\mathrm{Sn}-\mathrm{Au}) / \mathrm{Ni}$ interface in the diffusion couple. The total thickness $l$ of the compound layers is expressed as a power function of the annealing time $t$ by the equation $l=k\left(t / t_{0}\right)^{n}$, where $t_{0}$ is unit time, $1 \mathrm{~s}$. Here, $n$ is close to 0.5 at $T=$ $453-473 \mathrm{~K}$, but equal to 0.7 at $T=433 \mathrm{~K}$. This means that the growth of the compound layers is controlled by the volume diffusion of the constituent elements in each phase at $T=453-473 \mathrm{~K}$ but the interface reaction at the migrating $\mathrm{AuNiSn}_{8} /(\mathrm{Sn}-\mathrm{Au})$ interface contributes to the rate-controlling process at $T=433 \mathrm{~K}$. The overall growth rate of the compound layers is smaller for the ternary $(\mathrm{Sn}-\mathrm{Au}) / \mathrm{Ni}$ system than for the binary $\mathrm{Sn} / \mathrm{Au}$ system, but greater for the ternary $(\mathrm{Sn}-\mathrm{Au}) / \mathrm{Ni}$ system than for the binary $\mathrm{Sn} / \mathrm{Ni}$ and $\mathrm{Sn} / \mathrm{Cu}$ systems.

\section{Acknowledgements}

The authors are grateful to Messrs. K. Sakamoto and N. Kurokawa at Tyco Electronics AMP Co. Ltd., Japan for stimulating discussions. They also wish to thank Professor K. Ishida and Professor R. Kainuma at Tokohu University, Japan for their helpful information of the phase equilibria in the ternary $\mathrm{Au}-\mathrm{Ni}-\mathrm{Sn}$ system. The present study was supported by Tyco Electronics AMP Co. Ltd., Japan. The study was also partially supported by a Grant-in-Aid for Scientific Research from the Ministry of Education, Culture, Sports, Science and Technology of Japan.

\section{REFERENCES}

1) L. Zakraysek: Welding Res. Suppl. Nov. (1972) 536-541.

2) K. N. Tu: Acta Metall. 21 (1973) 347-354.

3) H. N. Keller: IEEE Trans. Components Hybrids Manuf. Tech. CHMT2 (1979) 180-195.

4) H. N. Keller and J. M. Morabito: Surf. Interface Anal. 3 (1981) 16-22.

5) J. O. G. Parent, D. D. L. Chung and I. M. Bernstein: J. Mater. Sci. 23 (1988) 2564-2572.

6) A. J. Sunwoo, J. W. Morris, Jr. and G. K. Lucey, Jr.: Metall. Trans. A 23 (1992) 1323-1332.

7) P. T. Vianco, P. F. Hlava and A. L. Kilgo: J. Electron. Mater. 23 (1994) 583-594.

8) D. R. Frear and P. T. Vianco: Metall. Trans. 25A (1994) 1509-1523.

9) S. Choi, T. R. Bieler, J. P. Lucas and K. N. Subramanian: J. Electron. Mater. 28 (1999) 1209-1215.

10) P. G. Kim and K. N. Tu: J. Appl. Phys. 80 (1996) 3822-3827.

11) A. M. Minor and J. W. Morris, Jr.: Metall. Mater. Trans. 31A (2000) 798-800.

12) J. H. Lee, J. H. Park, Y. H. Lee and Y. S. Kim: J. Mater. Res. 16 (2001) 1249-1251.

13) H. G. Song, J. P. Ahn, A. M. Minor and J. W. Morris, Jr.: J. Electron. Mater. 30 (2001) 409-414.

14) M. O. Alam and Y. C. Chan: Chem. Mater. 15 (2003) 4340-4342.

15) M. O. Alam and Y. C. Chan: J. Mater. Res. 19 (2004) 1303-1306.

16) C. M. Chen and S. W. Chen: Acta Mater. 50 (2002) 2461-2469.

17) M. Mita, M. Kajihara, N. Kurokawa and K. Sakamoto: Mater. Sci. Eng. A 403 (2005) 269-275.

18) M. Kajihara, T. Yamada, K. Miura, N. Kurokawa and K. Sakamoto: Netsushori 43 (2003) 297-298.

19) T. Yamada, K. Miura, M. Kajihara, N. Kurokawa and K. Sakamoto: J. Mater. Sci. 39 (2004) 2327-2334.

20) T. Yamada, K. Miura, M. Kajihara, N. Kurokawa and K. Sakamoto: Mater. Sci. Eng. A 390 (2005) 118-126.

21) T. Takenaka, S. Kano, M. Kajihara, N. Kurokawa and K. Sakamoto: Mater. Sci. Eng. A 396 (2005) 115-123.

22) M. Mita, K. Miura, T. Takenaka, M. Kajihara, N. Kurokawa and K. Sakamoto: Mater. Sci. Eng. B 126 (2006) 37-43.

23) T. Takenaka, S. Kano, M. Kajihara, N. Kurokawa and K. Sakamoto: 
Mater. Trans. 46 (2005) 1825-1832.

24) K. Suzuki, S. Kano, M. Kajihara, N. Kurokawa and K. Sakamoto: Mater. Trans. 46 (2005) 969-973.

25) T. Takenaka, M. Kajihara, N. Kurokawa and K. Sakamoto: Mater. Sci. Eng. A 406 (2005) 134-141.

26) T. Takenaka and M. Kajihara: Mater. Trans. 47 (2006) 822-828.

27) Y. Muranishi and M. Kajihara: Mater. Sci. Eng. A 404 (2005) 33-41.

28) T. Takenaka, M. Kajihara, N. Kurokawa and K. Sakamoto: Mater. Sci. Eng. A 427 (2006) 210-222.

29) Y. Yato and M. Kajihara: Mater. Sci. Eng. A 428 (2006) 276-283.

30) T. Hayase and M. Kajihara: Mater. Sci. Eng. A, in press.

31) T. B. Massalski, H. Okamoto, P. R. Subramanian and L. Kacprzak:
Binary Alloy Phase Diagrams (ASM International, Materials Park, OH, 1990) vol. 1, p. 434.

32) M. Kajihara: Acta Mater. 52 (2004) 1193-1200.

33) X. J. Liu, M. Kinaka, Y. Takaku, I. Ohnuma, R. Kainuma and K. Ishida: J. Electron. Mater. 34 (2005) 670-679.

34) Y. L. Corcoran, A. H. King, N. de Lanerolle and B. Kim: J. Electron. Mater. 19 (1990) 1177-1183.

35) M. Kajihara: Mater. Sci. Eng. A 403 (2005) 234-240.

36) M. Kajihara: Mater. Trans. 46 (2005) 2142-2149.

37) M. Kajihara: Def. Diff. Forum 249 (2006) 91-96.

38) M. Kajihara: Mater. Trans. 47 (2006) 1480-1484.

39) M. Onishi and H. Fujibuchi: Trans. JIM 16 (1975) 539-547. 